\title{
PRODROMAL SYMPTOMS IN MYOCARDIAL INFARCTION
}

\author{
BY \\ PATRICK MOUNSEY \\ From the Postgraduate Medical School of London \\ Received May 2, 1950
}

Sampson and Eliaser in an article entitled “ The Diagnosis of Impending Acute Coronary Arterial Occlusion " in 1937 described 29 cases " exhibiting attacks of præcordial pain of prolonged duration which," they considered, " might represent a precursor phenomenon of characteristic acute coronary arterial occlusion." Feil, in the same year, described fifteen more cases of this syndrome, which he named "preliminary pain in coronary thrombosis." Brill in 1938, in a review of earlier clinical reports on the subject, points out that, although the concept appeared new, it had already received mention by earlier authors and quotes Herrick (1912), Parkinson and Bedford (1928), Levine (1929), Willius (1936), and Conner and Holt (1930), who mention the occurrence of transitory chest pain before myocardial infarction of a nature different from previous anginal attacks. More recently, Langston (1939) has described a small series and Yater (1948) a large series of 60 cases in a review of coronary artery disease in men under the age of forty. It is interesting to note that, among earlier authors, Caleb Parry in 1799, described a case which, in the light of present knowledge, almost certainly belonged to this group.

\section{General Considerations}

The subject of prodromal symptoms in myocardial infarction is a difficult one, since it lies in the ill-defined borderline state between the clinical syndrome of angina of effort and the pathological state of myocardial infarction which has been referred to by Blumgart et al. (1940) as " coronary failure." In this state, angina pectoris of many different types may be met, almost protean in its minor variations, yet constant in its major essentials, and from this-state the patient may return to normal health, may proceed to or continue a long history of angina of effort, or may go on to myocardial infarction. The relative incidence of these three modes of termination is not obtainable in a hospital series, since few of those who do not suffer infarction are referred to hospital. Hospital records, however, provide good facilities for estimation of the relative frequency of such anginal prodromal symptoms in myocardial infarction and such a survey is attempted in this paper.

It is suggested that prodromal symptoms occur sufficiently frequently in myocardial infarction to make a recognizable clinical group. If this assumption is correct, its potential importance in the prophylactic treatment of myocardial infarction in such cases with rest and possible anti-coagulant therapy is important, as suggested by Wood (1949).

\section{InCidence of Prodromal Symptoms in Myocardial Infarction}

In an attempt to assess the relative frequency of prodromal symptoms in myocardial infarction, it was necessary to include in the series only those cases of myocardial infarction that allowed a clear decision to be made as to whether or not these were present and in which evidence of myocardial infarction was definite. Criteria for inclusion in the series were as follows. 
1. Post-mortem evidence or good electrocardiographic evidence that myocardial infarction had occurred. (In the earlier years, standard and CR leads alone were used; later the unipolar præcordial and limb leads were added.)

2. Clear clinical evidence of the exact time of the occurrence of infarction (except where serial electrocardiograms fixed the time accurately).

3. A good history of the events preceding infarction.

4. In the "prodromal" group, a history of anginal pain usually with atypical features or intensification or change in character of previous angina, preceding myocardial infarction by not more than three months.

Cases not fulfilling these criteria were rejected.

In a series of 139 cases of myocardial infarction acceptable by the above criteria, who were admitted to Hammersmith Hospital over a period of fourteen years, 40 showed prodromal symptoms, giving an incidence of 29 per cent.

\section{Comparison of Etiological factors and Prognosis in the Groups with and Without Prodromal Symptoms}

General factors. No significant differences were found in the age distribution, sex incidence or the incidence of hypertension in the prodromal group and the group without prodromal symptoms. The criteria for the diagnosis of hypertension were a systolic pressure of 150 or higher, or a diastolic pressure of 90 or higher. There was no significant difference in the incidence of diabetes mellitus in the two groups.

Previous history of typical angina of effort. In this series, 21 per cent of the prodromal group had a previous history of typical angina of effort as against 32 per cent in the group without prodromal symptoms. The border-line between angina of effort and the atypical pain of prodromal symptoms was often difficult to distinguish. There was a small group of patients with progressive angina pectoris in which the severity and frequency of attacks increased gradually over a period of years, finally culminating in myocardial infarction. These cases with a long progressive history (over 3 months) were excluded here from the prodromal group.

Angina of effort following myocardial infarction preceded by prodromal symptoms. Of the prodromal group, who survived the first myocardial infarction and were followed up, 79 per cent developed angina of effort, as compared with a figure of 59 per cent in the group without prodromal symptoms. There was, however, no significant difference in incidence if, from the latter group, a small sub-group of 14 cases who had no pain either at the time of myocardial infarction or afterwards be excluded. The angina following myocardial infarction is often atypical, lasting longer than usual and sometimes coming on at rest. For that reason it was difficult to obtain a clear history of prodromal symptoms preceding a second or a third myocardial infarction in patients with such angina, and only one case is included in this series. Of those who did not develop angina after a first myocardial infarction, none had prodromal symptoms before the second infarction.

Fatality rate. In the prodromal group, 39 cases had prodromal symptoms preceding their first attack of myocardial infarction and of these 5 terminated fatally, giving a fatality rate of 13 per cent. Of four cases in this group who had a second myocardial infarction, only one had clearly recognizable prodromal symptoms and this patient died. The overall fatality rate, without taking into account previous or subsequent attacks of myocardial infarction, was 15 per cent. In the group without prodromal symptoms, 30 patients died after a first attack of myocardial infarction giving a fatality rate of 30 per cent; 17 died out of 26 who had a second attack, and three out of three died who had a third attack. The overall fatality rate, without taking into account previous or subsequent attacks of myocardial infarction was 50 per cent. The fatality rate in the two groups is, however, not strictly comparable, since, following the introduction of anticoagulant therapy, a greater number of cases in the prodromal group received treatment than in the other group. 


\section{Prodromal Symptomatology}

Total duration. The shortest time between the onset of pain and the occurrence of myocardial infarction was three days, the longest by arbitrary definition twelve weeks. In thirteen cases prodromal symptoms occupied less than one week; in seven cases less than two weeks; in six cases less than three weeks; in eleven between three and eight weeks; and in three cases three months. The average duration of prodromal symptoms was three and a half weeks.

Character of the pain. The onset of the pain was usually described as being sudden, but on careful questioning patients would often admit to vague substernal discomfort of the same type some weeks earlier. The pain was typical anginal pain in site and radiation, being sternal or præcordial, radiating in some cases to the arms, shoulders, neck, jaws, or epigastrium. In character it was most often constricting, sometimes a dull ache.

Duration of individual attacks. This varied between five minutes and six hours. In fourteen cases, attacks never exceeded five minutes; in eight cases, fifteen minutes. In eight cases, they lasted up to thirty minutes; in one case up to one hour; in five cases, up to three hours; in one, up to six hours. In one case the pain was continuous for three weeks. In two cases, the duration of attacks was not recorded.

Precipitating factors. In eighteen cases, pain came on only with effort and never at rest. In four cases, pain came on at rest and was never related to effort; in one of these cases, there was definite association with worry; in another, the symptoms were unusual in that the pain was continuous for three weeks. In eighteen cases, attacks came on both on effort and at rest, out of which eleven had their first attack on effort, and six at rest, while in one the circumstances accompanying the first attack were unrecorded. There appeared to be no relationship between the varying lengths of attacks of pain and their precipitating factors. Emotion, meals, and temperature changes were less frequent precipitating factors, each occurring in only four to five cases in the group.

Relieving factors. Rest relieved the pain in all cases except seven, but in some this effect was not constant. Amyl nitrite relieved the pain in nine cases but did not relieve in one; in the remainder it was not tried or case records were inadequate.

Associated dyspnoea or congestive heart failure. Twenty cases suffered dyspnœa associated with the prodromal anginal pain. Thirteen of these had associated hypertension; the remaining seven had no evidence of respiratory disease or of cardiovalvular disease other than the myocardial infarction. Two cases finally presented with congestive cardiac failure at the time of myocardial infarction; both were hypertensive.

Periodicity of pain. The periodicity of pain varied greatly. In some cases it was six times a day; in others, once a week.

General trend. A crescendo quality was observed in 29 cases. This was seen in increased severity of pain in 20 cases; in increased frequency of attacks in 17; in diminished effort-threshold in 14 (i.e. less and less work was required to bring on the pain); in increased duration of attacks in 13. The remaining 11 cases showed no crescendo quality.

Analysis of the quality of prodromal pain in the present series showed that in all cases the pain possessed features that were atypical of classical angina of effort although the combination of these features varied from case to case. The most frequent finding was a crescendo nature in the symptoms during the short period of prodromal pain, which was seen in 29 out of 40 cases. The second distinguishing feature was the prolonged nature of the attacks. The third feature was the inconstant relation of the pain to effort: there was a group in which the pain was induced by effort, another in which the pain occurred at rest, and a third in which both occurred.

\section{Electrocardiograms during the Prodromal Period}

Electrocardiograms were obtained in ten cases during the prodromal period and were divisible into three main groups, those without clear evidence of myocardial ischæmia, those with evidence of ischæmia after exercise, and those with evidence of ischæmia at rest. There were four cases in 
the group without evidence of myocardial ischæmia. Three of these were hypertensive and had graphs that showed left ventricular preponderance (Fig. 1). The fourth case showed a right bundle branch block picture in the electrocardiogram (Fig. 2) which may have been evidence of myocardial ischæmia in this case. None of these cases were subjected to an exercise test.

Of the two cases showing an ischæmic type of graph on exercise, both showed S-T depression in leads V3 and V5 (Fig. 3), a pattern which is ascribed by Wilson (1947) to transient endocardial ischæmia.

The third group, which showed evidence of myocardial ischæmia at rest, consisted of four cases. The feature common to all four was the presence of S-T segment elevation and T wave inversion in the unipolar chest leads, without pathological Q waves (Fig. 4, 5, and 6).

Bayley (1943) pointed out that the pattern of deep symmetrical T wave inversion might or might not be followed by myocardial infarction and stated that it was caused by " acute local ventricular ischæmia " without infarction.

\section{Clinical, Electrocardiographic and Post-mortem Evidence of the Occurrence of Myocardial Infarction in the Prodromal Group}

In thirty-nine patients there was a clear-cut history of pain, worse than any previously experienced, which represented the summit of the crescendo of symptoms and was considered to mark the time of the occurrence of myocardial infarction. In twenty-three cases, the attack came on at rest, and in fifteen it occurred in bed. In fifteen cases, the pain came on whilst carrying out normal daily occupations. The duration of pain was usually prolonged; in fourteen cases more than twentyfour hours; in eight cases about twelve hours; in six cases, eight hours; in six cases, three hours; in three cases, one hour; in one case it was continuous with prodromal pain, and in one the time was unrecorded. In ten cases, the attack was associated with vomiting. In the remaining single case, not experiencing a major attack of pain at the time of myocardial infarction, the patient suffered repeated short anginal attacks at rest and finally showed signs of early congestive cardiac failure.

Electrocardiograms after the occurrence of myocardial infarction were obtained in all cases. In thirty cases, standard and unipolar limb and chest leads were taken. Here the diagnostic criteria were pathological $\mathrm{Q}$ waves with typical $\mathrm{S}-\mathrm{T}$ segment and $\mathrm{T}$ wave changes. In ten cases electrocardiographic evidence of myocardial infarction, although definite, was less complete. In three, the standard and CR1, CR3, and CR4 leads were taken; in four the standard and CR4 leads; in three the standard leads alone. Evidence of infarction in this sub-group lay in Pardee coving with a sharply inverted $\mathrm{T}$ wave; in addition, six cases showed pathological $\mathrm{Q}$ waves.

Four cases came to post-mortem examination, and in these the clinical diagnosis of myocardial infarction was confirmed.

\section{Pathology of Prodromal Symptoms}

In this series, evidence as to the pathogenesis of prodromal symptoms has been obtained from post-mortem data in four cases. One case was of special interest pathologically and is therefore reported in full here.

Case A. K. A hypertensive male, aged 53, a tailor's presser, who had previously been in good health, had a sudden attack of severe sub-sternal gripping pain on exertion. The pain lasted two to three minutes and disappeared on resting. During the next week he was symptom-free, except for slight dyspnœea on exertion. At the end of this time he had recurrences of angina of effort, at first once a day, later three or four times a day, which gradually became more severe. Finally, after a further week, he had a severe attack of pain at rest lasting twenty minutes, followed by three to four similar attacks at rest in the next twelve hours.

He was admitted to hospital with a provisional diagnosis of myocardial infarction and an electrocardiogram two days later (Fig. 4) showed an ischæmic pattern with deep symmetrical T wave inversion in all chest leads. There were no significant blood pressure changes during the 


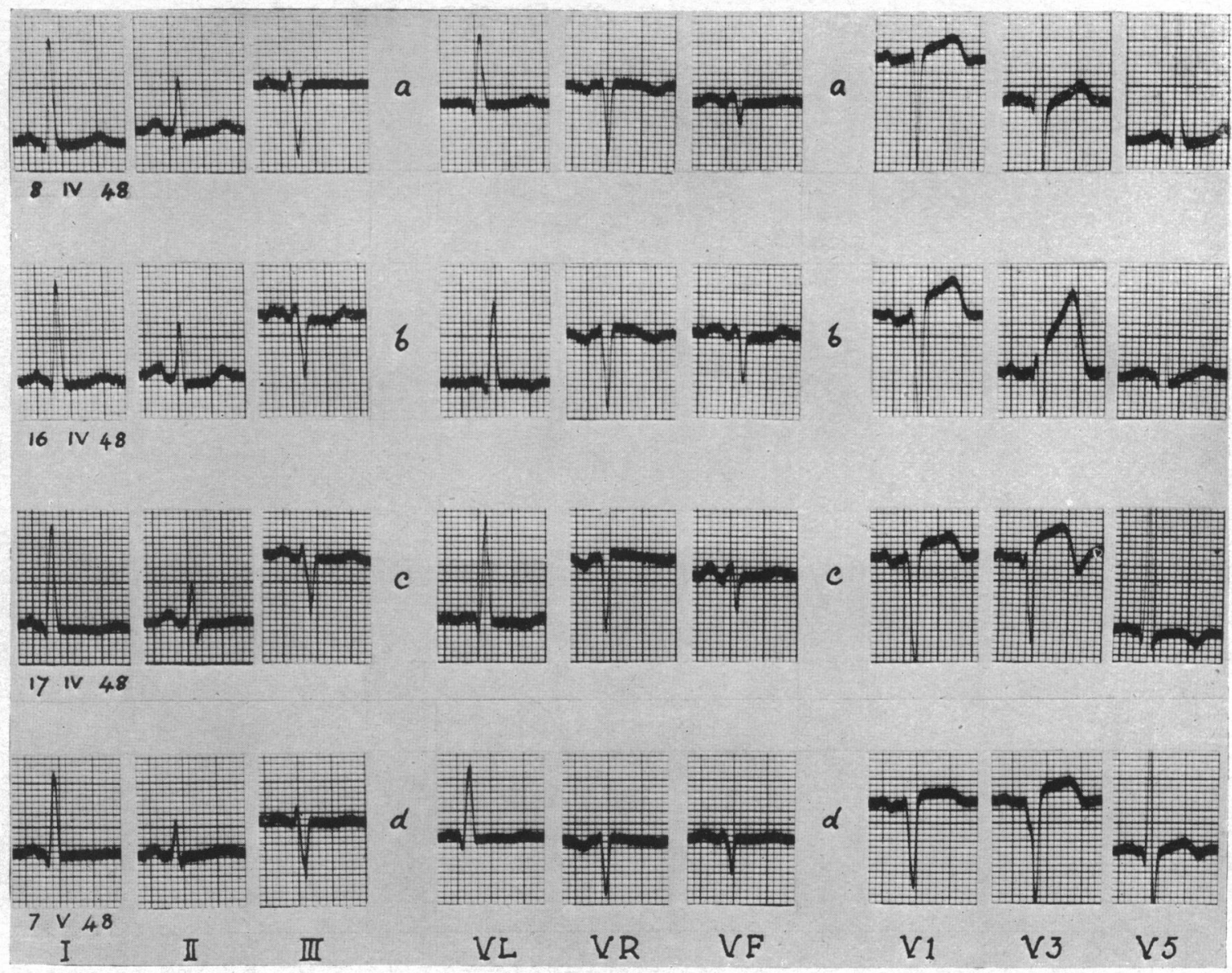

FIG. 1.-Case with no definite evidence of myocardial ischæmia during the prodromal period. Exercise test not performed. (a) EC during prodromal period; left ventricular preponderance; (b), (c), (d) progressive changes of acute anterior myocardial infarction.

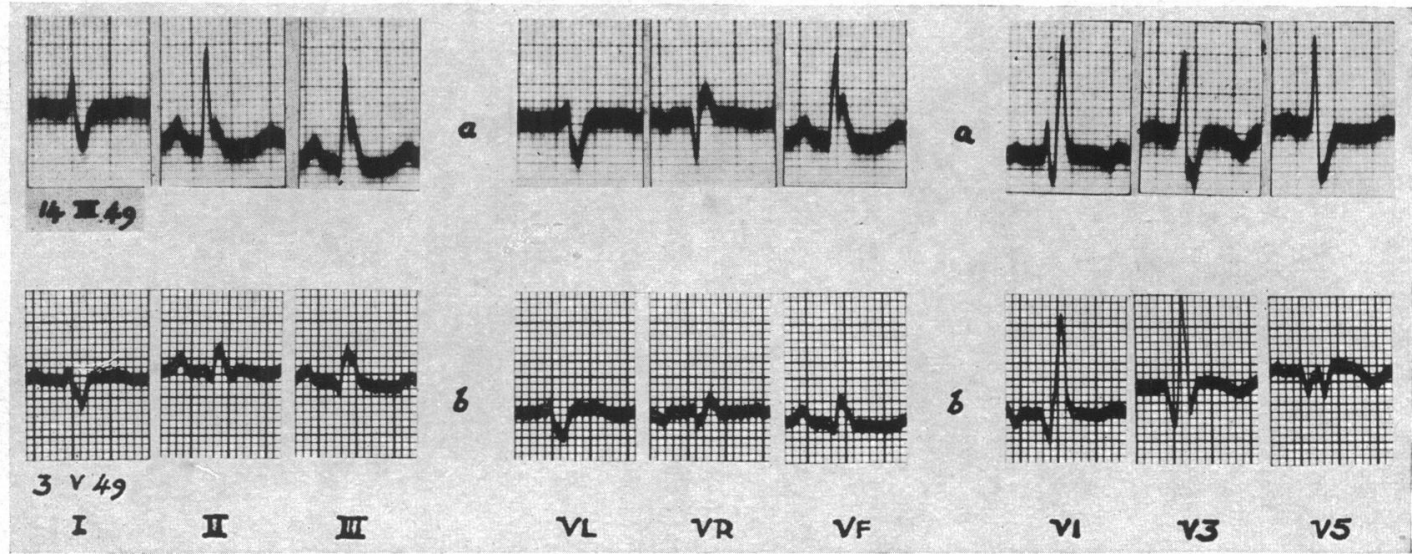

Fig. 2.-Case with no definite evidence of myocardial ischæmia during prodromal period. Exercise test not performed. (a) EC during prodromal period; R.B.B.Bl.; (b) acute anterior myocardial infarction. 


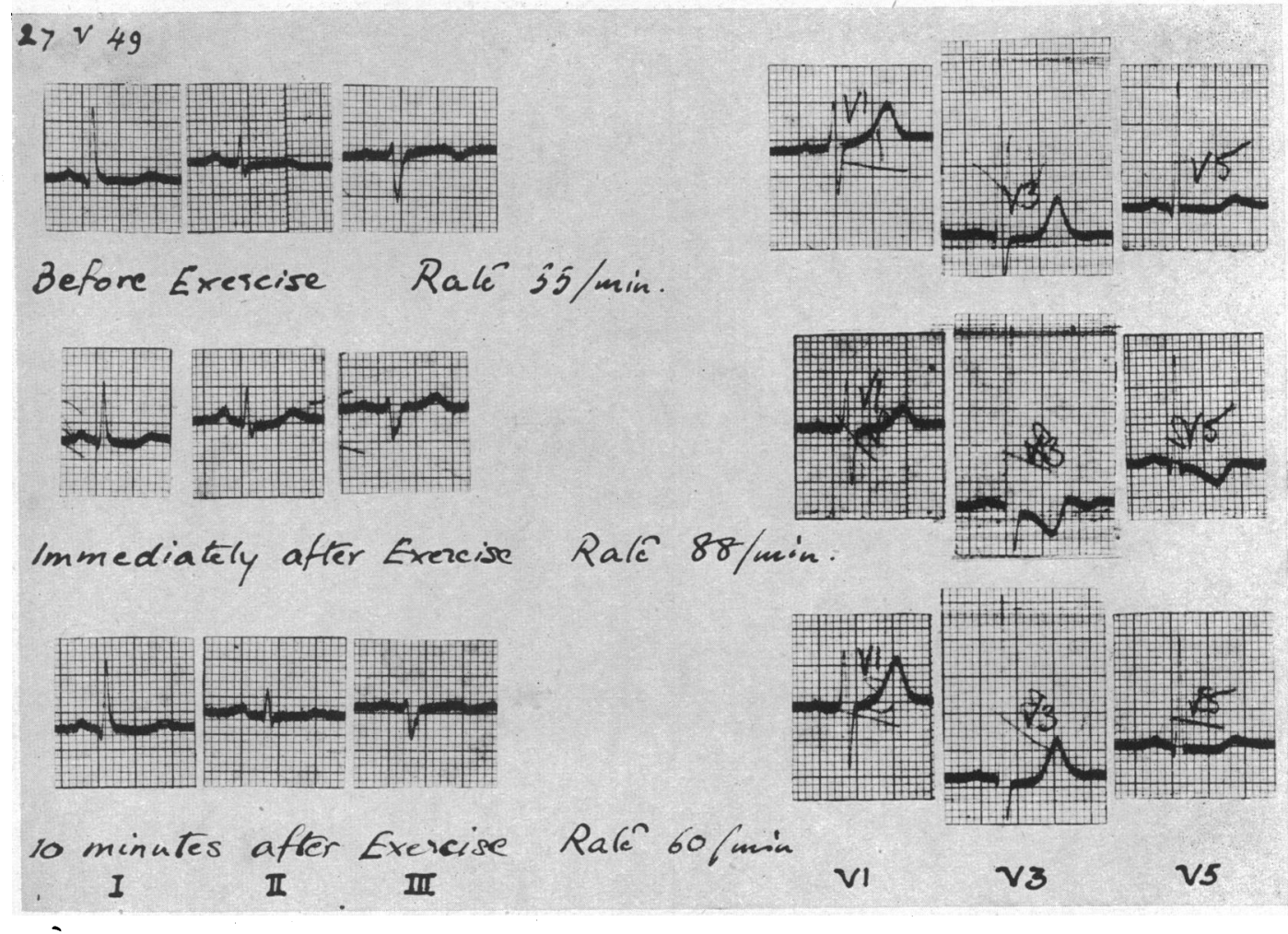

FIG. 3.-Case with evidence of myocardial ischæmia on exercise during the prodromal period. EC during prodromal period. Ischæmic change on exercise: S-T depression in V3 and diphasic T in V3.

attack. His hæmoglobin was $15.5 \mathrm{~g}$. per $100 \mathrm{ml}$. and his blood Wassermann reaction was negative. Immediate anticoagulant therapy with dicoumarol was started. The patient continued to have frequent short anginal attacks in bed, but these were always relieved by trinitrin tablets.

Electrocardiograms were taken daily and a series of ischæmic changes noted, the S-T segment in V3 first rising with a terminal biphasic $T$ wave and the development of a very small $Q$ wave. A graph taken after trinitrin showed more upright $\mathrm{T}$ waves in all chest leads and also a change in the QRS pattern in V3, which was considered to be due to altered position of the electrode. In the next graphs, taken at two-day intervals, there were no significant changes.

A week later, there was a further minor clinical incident, the patient complaining of mild but prolonged chest pain. An electrocardiogram showed the classical picture of an acute anteroseptal myocardial infarct with a QS deflection in V3 and S-T coving with inverted $T$ wave.

His general condition gradually deteriorated. There was no major prolonged anginal attack, but the signs of early congestive heart failure developed. The erythrocyte sedimentation rate rose steadily from a normal level on admission, while the white cell count fell; the blood pressure, though labile, also tended to fall. A low pyrexia developed during the last two days of life. He died suddenly on the eighteenth day after admission. Anticoagulant therapy had been continued uninterruptedly with satisfactory therapeutic prothrombin levels from the time of admission until death.

At post-mortem examination two points were looked for with especial interest; first, the exact age of the myocardial infarction in view of the prodromal ischæmic cardiographic changes; secondly, the nature of the slow occlusive process in the coronary arteries giving rise to this prolonged myocardial ischæmia. An extensive infarct of the left ventricle and septum was found, the 


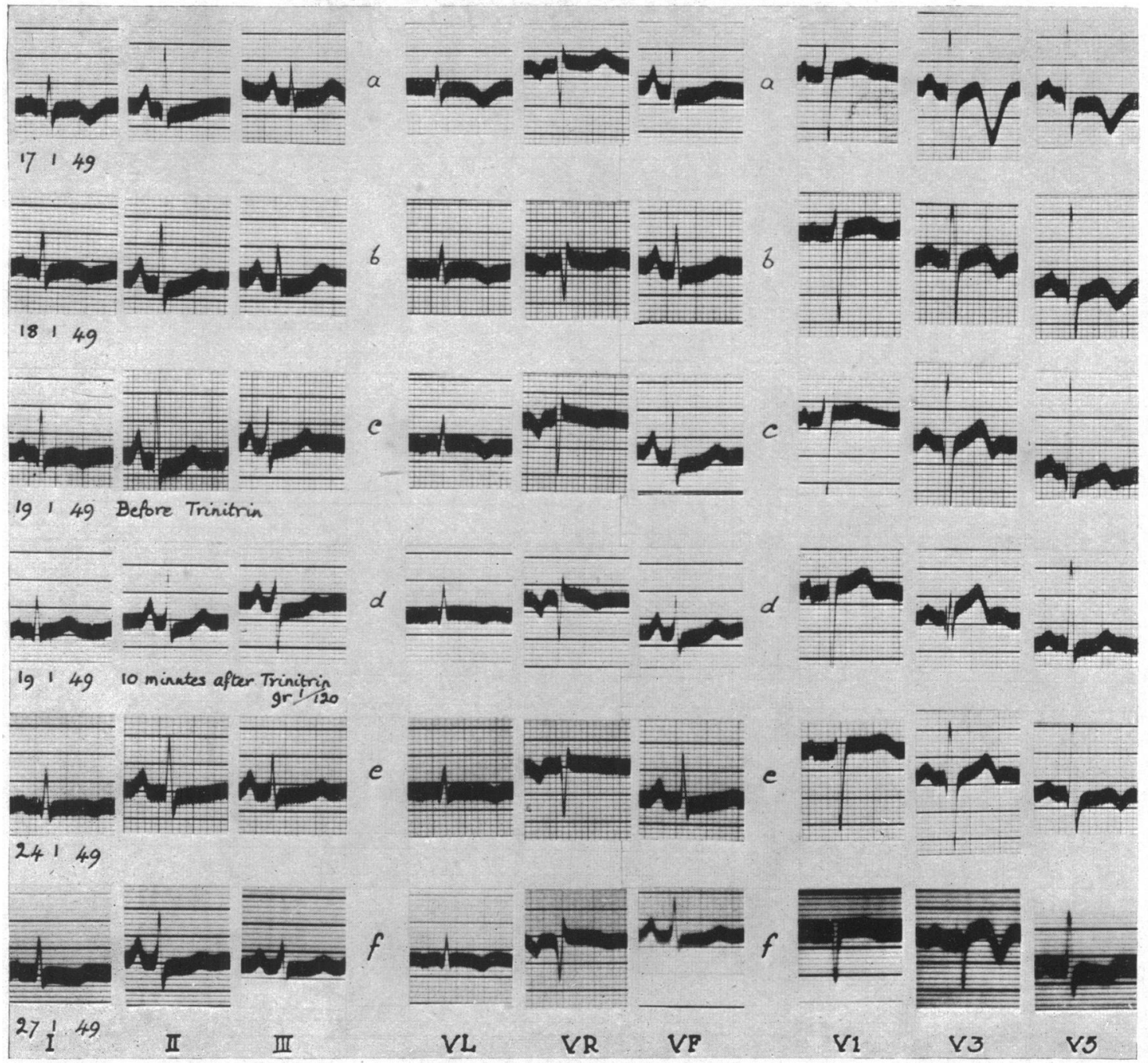

Fig. 4.-Case A. K., with evidence of myocardial ischæmia at rest during the prodromal period. (a)-(e) Cardiograms during prodromal period showing changing ischæmic patterns: $S-T$ elevation in V1 and V3. No definite pathological $Q$ waves. $T$ wave inversion in V3 and V5. (f) Acute anteroseptal myocardial infarction.

whole of the infarct appearing to be of the same age both on macroscopic and microscopic examination. The muscle fibre was visible as muscle but was a pale buff colour and softer than normal. There was no evidence of fibrosis either in the infarcted areas or elsewhere, and no areas of greater softening or endocardial thrombosis. In the ascending aorta, evidence of syphilitic aortitis was seen but there was no stenosis of the mouths of the coronary arteries. The right coronary artery was almost completely occluded by old, healed atheroma and thrombosis; the left circumflex was atheromatous but patent. The descending left coronary artery (Fig. 7 and 8) was occluded $6 \mathrm{~mm}$. below its origin by fresh purple-red thrombus only lightly adherent to the wall; below this the vessel was of good calibre. Histology here showed the arterial lumen to be partly narrowed by old healed atheroma and thrombosis; inside this a healing mural thrombus was seen, infiltrated with fibroblasts and containing strands of true collagen. On top of this there was a further layer, nearly closing the lumen, of very recent fibrin with entangled leucocytes and a few red cells. 


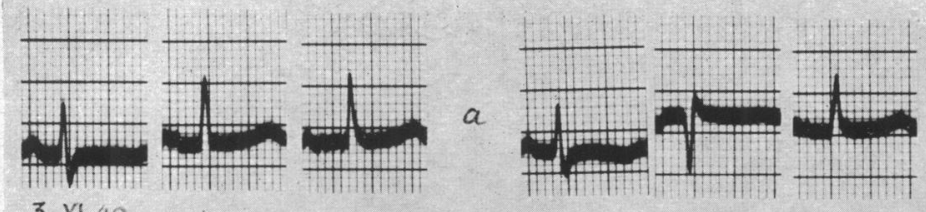

a
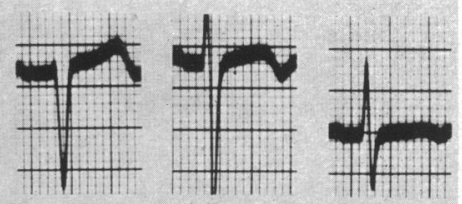

$3 \mathrm{~V} 49$

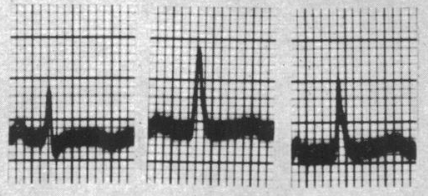

$9 \times 149$
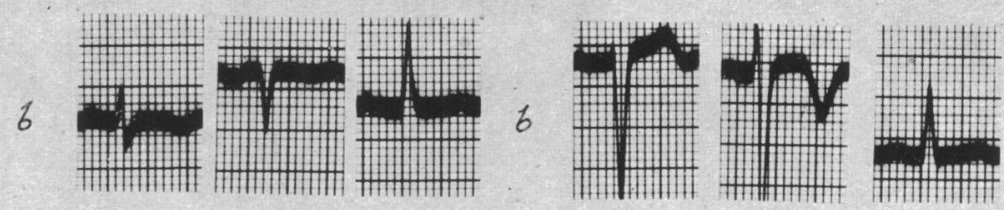

c
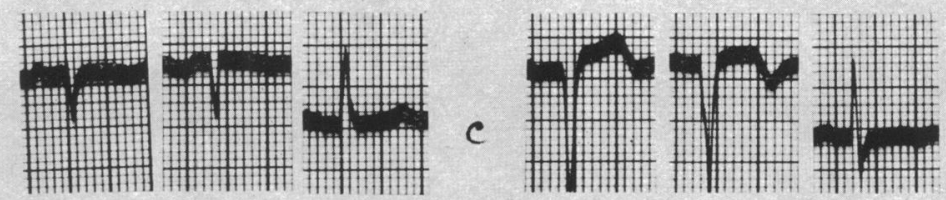

$V_{L}$

VR

VF

v1

v3

v5

FIG. 5. - Case with evidence of myocardial ischæmia at rest during the prodromal period. (a) and (b) Cardiograms during prodromal period. Changing ischæmic patterns; slight elevation and coving S-T in V3; sharp symmetrical inversion of T in V3; no pathological $Q$ waves; chest leads, one and two spaces up, also taken, but not illustrated here. (c) EC shows acute anteroseptal myocardial infarction.

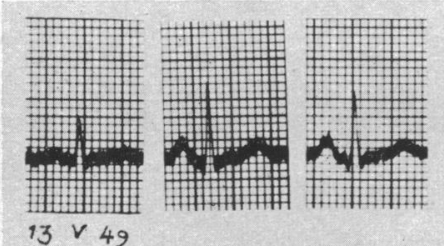

a

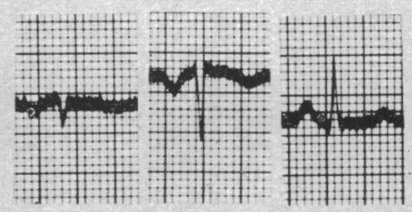

a

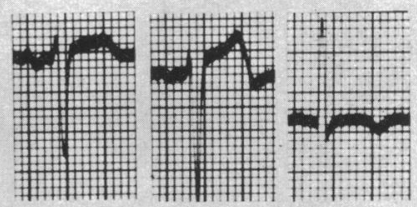

6

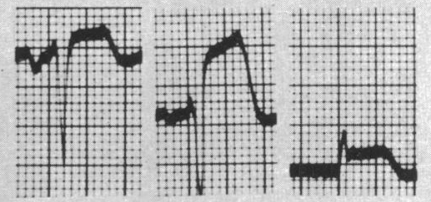

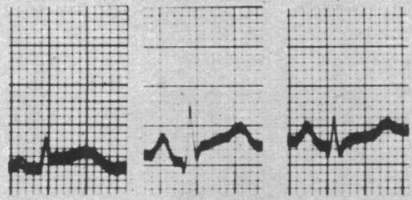

6

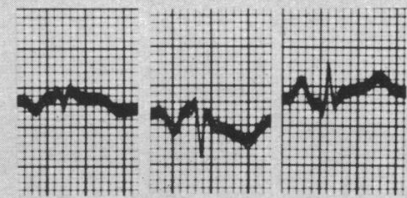

$14 \times 49$

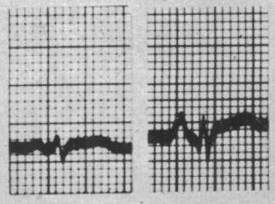

$17 \times 49$

I

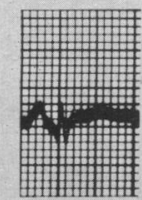

III
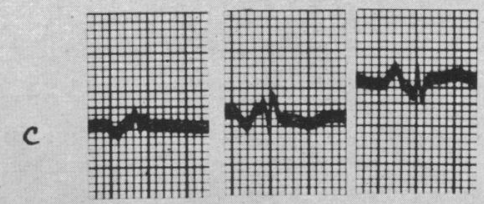

VL

$\checkmark R$

$\checkmark F$
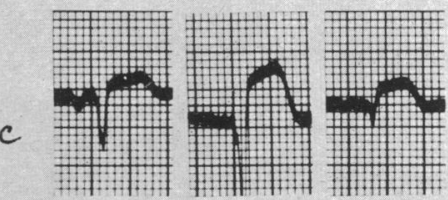

VI

$\sqrt{3}$

$\checkmark 5$

FIG. 6-Case with evidence of myocardial ischæmia at rest during the prodromal period. (a) EC during prodromal period; ischæmic pattern. S-T elevation in V3 with diphasic $T$ in $V 3$ and $T$ inversion in V5. (b), (c) EC shows acute extensive anterior myocardial infarction. 
It was thought that the mural thrombus undergoing organization in the left descending coronary artery corresponded with the onset of symptoms five weeks before death and that the superimposed recent thrombus and the myocardial infarct were terminal and probably twenty-four to forty-eight hours old

In a second case, a rather similar pathological picture was seen.

In the remaining two cases, evidence of a different pathology in the coronary arteries was found. In one, there was severe generalized coronary atherosclerosis with old occlusion of the left recurrent coronary artery and recent thrombotic occlusion of the right recurrent coronary artery which had previously supplied the collateral blood supply to the ischæmic area of muscle on the posterior wall of the left ventricle. The thrombus appeared to be of uniform age. Sections of the posterior wall of the left ventricle showed all stages of recent infarction from early necrosis up to absorption of fibres and also patches of old fibrosis. In the other case, in the wall of the left circumflex coronary artery hæmorrhage into an atheromatous plaque was seen (Fig. 9 and 10) which appeared to have ruptured into the lumen of the artery. From the point of rupture strands of fibrin radiated outwards into the fresh thrombus, which totally occluded the vessel lumen, as

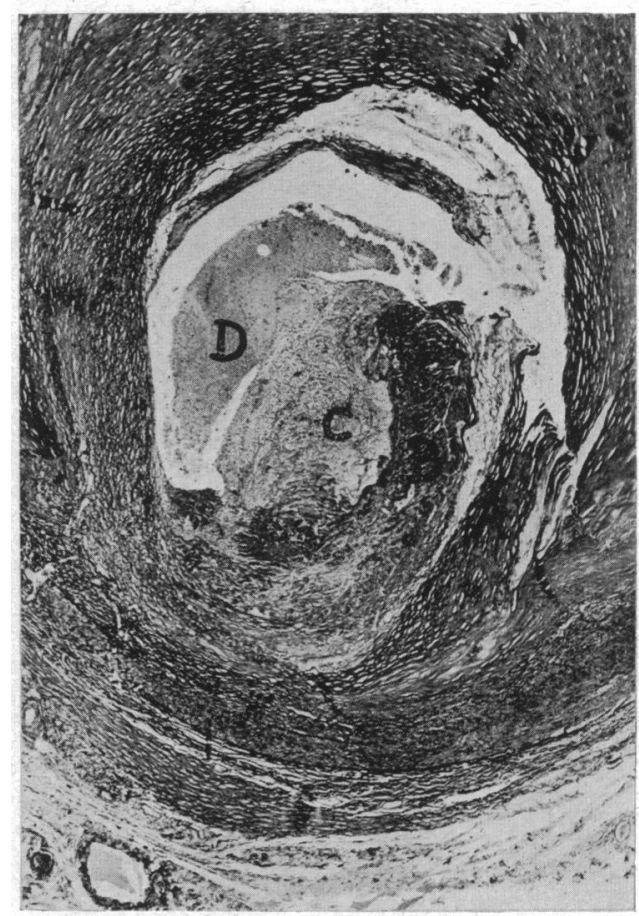

Fig. 7.-Case A. K., transverse section of the descending branch of left coronary artery $6 \mathrm{~mm}$. below its origin. Magnification, $\times 24$. For explanation of $\mathrm{A}, \mathrm{B}, \mathrm{C}$, and $\mathrm{D}$ see legend to Fig. 8.

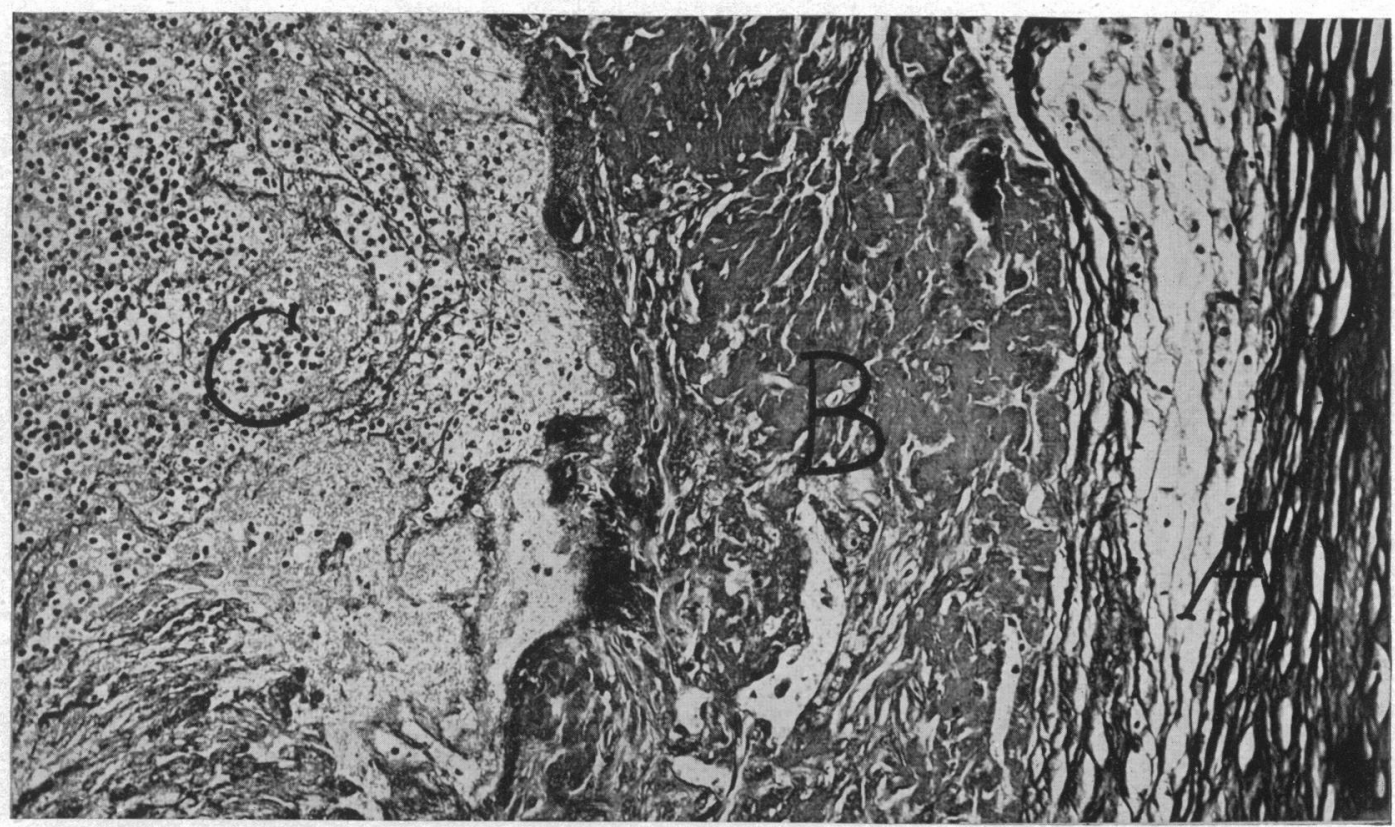

FIG. 8.- Higher power of same section as Fig. 7. Magnification, $\times 145$. (A) old atheroma; (B) healing mural thrombus infiltrated with fibroblasts and containing strands of collagen; (C) very recent fibrin with entangled leucocytes and a few red cells; (D) fresh thrombus. (D) is shown in Fig. 7 only. 


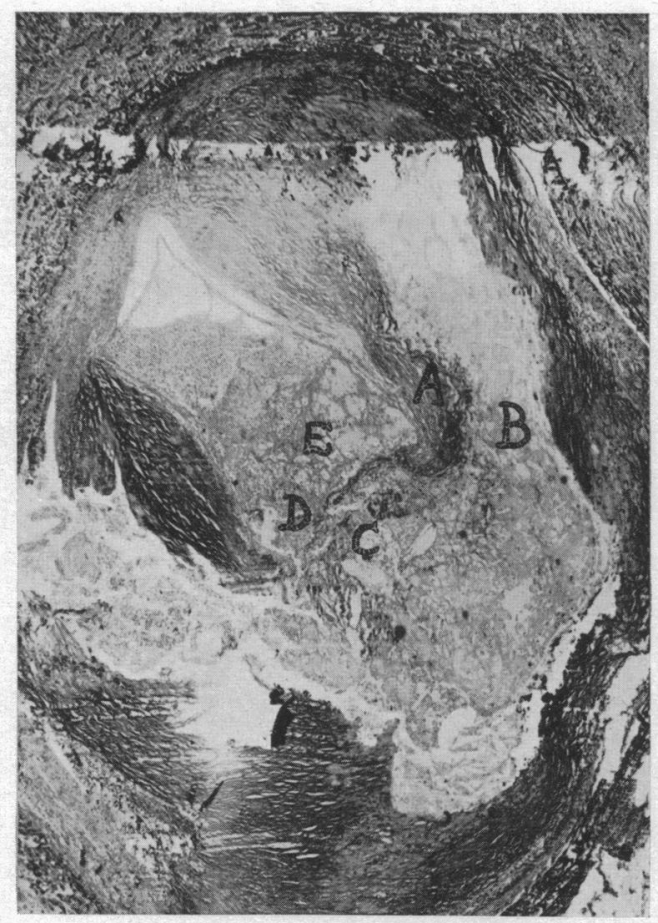

FIG. 9.-Transverse section of the proximal portion of the left circumflex coronary artery. Magnification, $\times 27$.

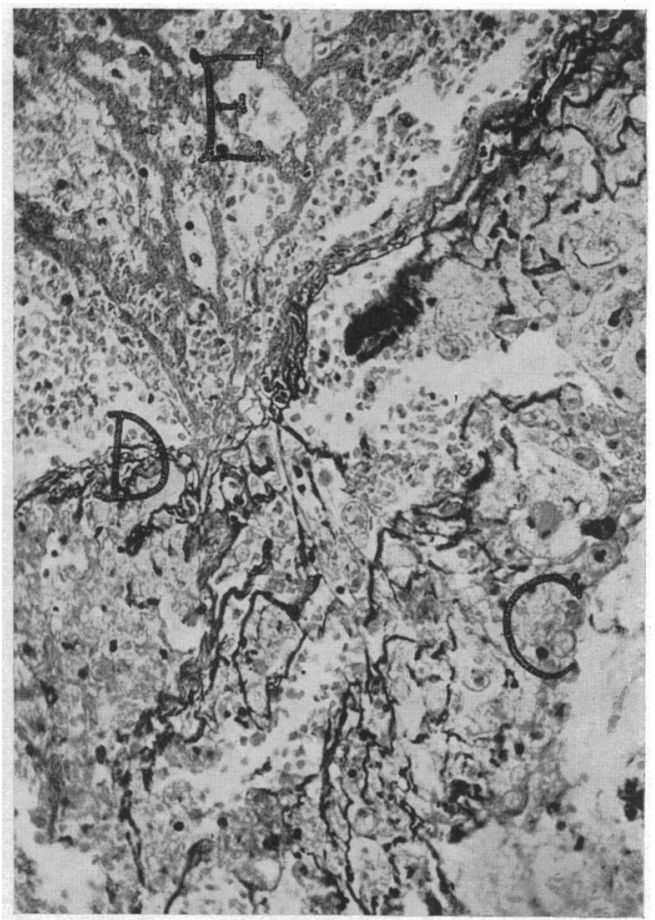

Fig. 10.-Higher power of same section. Magnification, $\times 190$

Key to Fig. 9 and 10: (A) severe atheroma; (B) atheromatous "abscess"; (C) hæmorrhage into atheromatous plaque; (D) interruption of intimal wall; (E) strands of fibrin radiating from $D$ into fresh unorganized thrombus occluding vessel lumen.

though the thrombus had grown from this point. In addition, a non-occlusive mural thrombus was seen in the left descending coronary artery. There was extensive recent infarction of the posterior wall of the left ventricle, in which different stages of infarction were seen. It is suggested that in the first case, slowly increasing arterial narrowing by atherosclerosis gradually reduced the blood supply to an already ischæmic zone of myocardium and caused recurrent localized muscle necrosis, and that the onset of prodromal symptoms corresponded with this terminal phase in a case of progressive coronary atherosclerosis. In the other case, the hæmorrhage into the atherosclerotic plaque was almost certainly the immediate precursor of the final thrombotic occlusion of the artery, but probably antedated it by not more than a week, since the red cells in it appeared well preserved. The onset of prodromal symptoms, a fortnight before that, may have been due to the older non-occlusive mural thrombus in the left descending coronary artery.

\section{Discussion}

The incidence of prodromal pain in this series of cases of myocardial infarction was 29 per cent. This is lower than that of Sampson and Eliaser and of Feil, in whose series it was 48 per cent and 50 per cent respectively. Yater, in a series of men under 40 , found an incidence of 9.5 per cent. Many different factors may account for this difference: the errors inherent in statistics applied to small groups, clinical and electrocardiographic criteria for inclusion of cases and also possibly variation in the recording of the symptomatology of the disease.

The fatality rate in this series in the prodromal group, without taking into account histories of 
previous coronary occlusions, was 15 per cent compared with 34 per cent and 43 per cent in Sampson and Eliaser's and Yater's series respectively. The fatality rate in the group without prodromal symptoms was 50 per cent both in the present series and in that of Sampson and Eliaser; in Yater's series it was 53 per cent for the total group of cases of myocardial infarction reviewed. The figures in the three series vary widely, but in all reports there was a lower fatality rate in the prodromal group than in the group without prodromal symptoms.

In previous series, the use of electrocardiograms of only standard leads detracts greatly from their value at the present-time. Electrocardiographic changes that occur during the prodromal period can today be better assessed by full unipolar lead exploration in addition to the standard leads. It is noteworthy that in the present series, in the prodromal pain group, some patients showed evidence of severe myocardial ischæmia at rest and that, of those who had a negative resting graph, no patient on whom an exercise test was performed failed to show evidence of ischæmia.

Results of erythrocyte sedimentation tests, white cell counts, temperature records, and blood pressure changes are not recorded here. Typical changes were observed after the occurrence of myocardial infarction. Results obtained during the prodromal period were usually negative, although minor changes were sometimes observed. In all cases in the prodromal group, the hæmoglobin was within normal limits. The blood Wassermann reaction was positive in one case only, in whom there was no clinical or radiological evidence of syphilitic aortitis and the electrocardiographic diagnosis of myocardial infarction certain.

Post-mortem findings in this series offered evidence to support the concept that the cause of prodromal pain is a gradually decreasing lumen in a coronary artery with consequent increasing myocardial ischaemia, finally culminating in myocardial infarction with coronary occlusion. Such a pathological process, whether the occluding arterial lesion be a growing thrombus, subintimal hæmorrhage, atheromatous plaque, or gradual sclerosis, forms a reasonable explanation for the development of atypical angina pectoris as a prodromal symptom in myocardial infarction.

\section{SUMMARY}

Earlier studies of prodromal symptoms in myocardial infarction are briefly reviewed and the relation of this syndrome to " coronary failure " discussed.

A series of 40 cases of myocardial infarction with prodromal symptoms is described, in which most cases suffered prodromal symptoms de novo, but in which a few experienced a new type of anginal pain following on a long history of typical angina of effort.

The clinical and electrocardiographic features are described.

The necropsy findings support the concept that the cause of prodromal pain is a gradually decreasing lumen of a coronary artery with consequent increasing myocardial ischæmia, finally culminating in myocardial infarction and coronary occlusion.

The importance of the clinical diagnosis of this syndrome lies in the prophylactic treatment of myocardial infarction with rest and, possibly, anticoagulant therapy.

I am indebted to Professor McMichael for the facilities for carrying out this work and to both him and Dr. Wallace Brigden for encouragement and much helpful criticism. I am also indebted to Dr. C. V. Harrison for his criticism of the interpretation of the pathological sections and to Dr. Paul Wood for his criticism of some of the interpretations of electrocardiograms.

This paper is an abstract from a thesis submitted for the M.D. degree at Cambridge University, and I am indebted to Sir Lionel Whitby, Regius Professor of Physic, Cambridge University, for permission to publish it.

\section{REFERENCES}

Bayley, R. H. (1943). Amer. Heart J., 26, 823.

Blumgart, H. L., Schlesinger, M. J., and Davis, D. (1940). Ibid., 19, 1. 
Brill, I. (1938). Ann. intern. Med., 12, 365.

Conner, L. A., and Holt, E. (1930). Amer. Heart J., 5, 705.

Feil, H. (1937). Amer. J. med. Sci., cxc. iii, 42.

Herrick, J. B. (1912). J. Amer. med. Ass., 59, 2015.

Langston, W. (1939). Sth. med. J., III, 32, 333.

Levine, S. A. (1929). Medicine, 8, 245.

Parkinson, J., and Bedford, D. E. (1928). Lancet, 1, 4.

Parry, Caleb.'(1799). An Inquiry into the Symptoms and Causes of Syncope Anginosa, commonly called Angina Pectoris. Cadell and Davies, London, 28.

Sampson, J. J., and Eliaser, M. (1937). Amer. Heart J., 13, 675.

Willius, F. A. (1936). Proc. Mayo Clin., 11, 414.

Wilson, F. N., Rosenbaum, F. F., and Johnston, F. D. (1947). Advances Internal Medicine, New York Inter-science Publications, 2, 42.

Wood, P. H. (1949). Brit. Med. J., 1, 26.

Yater, W. M. et al. (1948). Amer. Heart J., 36, 334. 